\title{
ESTADO DE DERECHO E IGUALDAD: PODER EJECUTIVO «ILIMITADO» COMO RESPUESTA A LA CRISIS DE LA COVID-19 Y VULNERACIÓN DE LOS DERECHOS LGBTI EN HUNGRÍA Y POLONIA
}

Rule of law and equality: "Illimited" executive power in response to COVID-19 crisis and LGBTI rights infringement in Hungary and Poland

\author{
JUAN FRANCISCO BARROSO MÁRQUEZ \\ Universidad de Extremadura \\ juanbarroso@unex.es
}

Cómo citar/Citation

Barroso Márquez, J. F. (2021).

Estado de derecho e igualdad: poder ejecutivo «ilimitado» como respuesta a la crisis de la COVID-19 y vulneración de los derechos LGTBI en Hungría y Polonia. lgualdadES, 4, 183-214. doi: https://doi.org/10.18042/cepc/lgdES.4.06

(Recepción: 01/07/2020; aceptación tras revisión: 19/04/2021; publicación: 30/06/2021)

\section{Resumen}

En este artículo analizaremos la conexión existente entre el Estado de derecho, el derecho fundamental a la igualdad y los derechos LGTBI en la Unión Europea. Primero, conceptualizaremos el Estado de derecho y, como parte de su versión material o sustantiva, el papel que juegan los derechos fundamentales y, en concreto, la igualdad, donde se incluyen los denominados derechos LGTBI. Tras ello, utilizaremos los ejemplos que nos proporcionan las reformas llevadas a cabo en Hungría, donde se ha eliminado la posibilidad del cambio legal de género y se ha reformado la Ley Fundamental para prohibir la adopción de las parejas LGTBI; y en Polonia, donde se han creado zonas libres de ideología LGTBI. Todo esto, producido en un contexto previo de reformas iliberales que ha sido agravado por la respuesta gubernamental 
de ambos Estados a la COVID-19, con la que han logrado acumular más poder. El objetivo es, por tanto, analizar las consecuencias que la erosión del Estado de derecho tiene sobre la protección de los derechos LGTBI.

\section{Palabras clave}

Estado de derecho; igualdad; derechos LGTBI; Hungría; Polonia; COVID-19.

\section{Abstract}

In this paper we will analyse the relationship between Rule of Law, equality as a fundamental right and LGBTI rights in the European Union. First, we will conceptualise the Rule of Law and, as a content of its thick version, the role played by fundamental rights and, concretely, equality and LGBTI rights as a part of it. After that, we will use the examples given by the recent reforms in Hungary, where the possibility of legal gender change has been deleted and the Fundamental Law has been amended to prohibit LGBTI adoption, and in Poland, where LGBTI-free zones have been created; produced in a previous context of illiberal reforms, worsened by the governmental response of both States to face COVID-19, which has been used to seize more power. Our goal is to analyse the consequences that the Rule of Law erosion has over the protection of LGBTI rights.

\section{Keywords}

Rule of Law; equality; LGBTI rights; Hungary; Poland; COVID-19. 


\section{SUMARIO}

I. INTRODUCCIÓN. II. ESTADO DE DERECHO, IGUALDAD Y DERECHOS LGTBI. III. VULNERACIÓN DE DERECHOS LGTBI EN TIEMPOS DE PANDEMIA: 1. Contexto iliberal. 2. La respuesta de Hungría y Polonia a la COVID-19. 3. Medidas anti-LGTBI en Polonia. 4. Medidas anti-LGTBI en Hungría. 5. La respuesta de la UE ante la vulneración de los derechos LGTBI. IV. CONCLUSIONES. BibLIOGRAFía.

\section{INTRODUCCIÓN}

Los derechos fundamentales se constituyen como uno de los pilares sobre los que se ha construido la Unión Europea en sus últimos años. En concreto, la igualdad en todas y cada una de sus variantes ha ocupado un papel central y en su seno queda incardinada la interdicción de la discriminación por motivos de orientación sexual e identidad de género, traducida en lo que comúnmente conocemos como «derechos LGTBI» ${ }^{1}$. Son también uno de los elementos

\footnotetext{
Arroyo Gil (2019) señala que no existen los «derechos LGTBI» como tal, sino que se trata de una serie de manifestaciones relacionadas con la orientación sexual y la identidad de género que presentan problemas en relación con ciertos derechos fundamentales y que, por tanto, estrictamente hablando no existen derechos propios o específicos de las personas LGTBI, más allá del derecho a no ser discriminado por razón de orientación sexual o identidad de género. Sin embargo, estas manifestaciones surgen de una construcción social donde la hetero-cissexualidad se instauró (y sigue instaurada) como canon imperante. En este marco fáctico las personas cis-hetero-normativas no tienen necesidad de ser protegidas por su orientación sexual o identidad de género, sino que únicamente las personas pertenecientes al colectivo LGTBI, las que se salen de esta norma, son las que ven surgir la necesidad de que exista un estatuto jurídico o conjunto de derechos (de configuración legal) que satisfaga las necesidades concretas de protección del colectivo. Estamos en un sistema en el que no es difícil encontrar situaciones de discriminación por motivos de orientación sexual e identidad de género, pero estas nunca tienen como protagonistas a las personas cis-hetero-normativas, sino que siempre afectan a los miembros del colectivo LGTBI. Por ello, aunque desde un prisma estrictamente jurídico sería posible proteger a una persona cis-hetero de este tipo de discriminación, la (triste) realidad nos demuestra que únicamente las personas LGTBI, por el hecho
} 
basilares de la concepción robusta de Estado de derecho y, por ello, debemos analizar las posibles implicaciones de la erosión del Estado de derecho en varios de sus Estados miembros respecto de la protección de los derechos LGTBI en la UE².

Sin embargo, no podemos analizar estas medidas de forma individualizada, sino que debemos incardinarlas en el contexto de reformas iliberales ${ }^{3}$ que se han producido y se siguen produciendo en Hungría y Polonia, hasta el punto de que la Unión Europea ha iniciado respecto de sendos Estados el procedimiento contenido en el artículo 7.1 TUE, cuyo objetivo es constatar la existencia de un riesgo claro de violación grave del Estado de derecho. Este escenario se ha visto agravado, además, por la respuesta que han dado a la COVID-19, de modo que también analizaremos las medidas adoptadas por ellos para hacer frente a la crisis pandémica.

\section{ESTADO DE DERECHO, IGUALDAD Y DERECHOS LGTBI}

La descripción tradicional del Estado de derecho es la proporcionada por F. J. Stahl, como aquel Estado en el que se determina «con precisión, a través de la forma del derecho, tanto la dirección y los límites de su propia acción como el ámbito de libertad de sus ciudadanos» (Böckenförde, 2000: 24). Se configura como límite para los poderes públicos, pero sus implicaciones han ido evolucionando a lo largo de la historia, ya que el Estado de derecho

de serlo, necesitan la existencia de un estándar jurídico reforzado de protección y, por tanto, de facto sí es posible denominar al estatuto jurídico (de configuración legal) que surge para una persona por el mero hecho de pertenecer al colectivo LGTBI como «derechos LGTBI», teniendo en cuenta que, a su vez, estos se configuran como una concreción del derecho (fundamental) a la igualdad.

2 Analizaremos la creación de zonas libres de ideología LGTBI (Polonia), la eliminación del cambio legal de género (Hungría) y la prohibición de la adopción de parejas LGTBI (Hungría).

3 Las democracias iliberales fueron definidas por Fareed Zakaria (1997) como aquellos sistemas en que las fuerzas políticas que acceden al poder siguiendo los cauces propios de la democracia representativa, una vez lo alcanzan suprimen los controles propios del constitucionalismo para lograr retenerlo. Es común encontrar el término iliberal en la doctrina, pero algunos entienden que hablar de democracia iliberal resulta de todo punto un oxímoron (Müller, 2016: 224). Desde nuestro punto de vista, entendemos que lo más adecuado sería utilizar el término iliberalismo o referirnos a regímenes o Gobiernos iliberales, cuyo objetivo es la realización de un «contra-proyecto constitucional» (Blokker, 2016: 260-265). 
es un concepto adaptativo, esto es, que reacciona a las necesidades contemporáneas y guarda relación con el contexto (Drinóczi y Bień-Kacala, 2021: 10). En un primer momento, surgió en la forma que actualmente conocemos como thin version (Konstantinides, 2020: 55) o concepción formal del Estado de derecho, que se centra en la promulgación del derecho, su claridad y la dimensión temporal de sus efectos (Candia-Falcón, 2016: 11). Como consecuencia de esta concepción, el propio Joseph Raz admitió que existe el riesgo de que debamos afirmar que cumplen con el Estado de derecho aquellos regímenes cuyas leyes son moralmente cuestionables, siempre que cumplan con los requisitos formales que lo componen (Craig, 1997: 468).

Sin embargo, todas las decisiones de la mayoría en las democracias modernas quedan limitadas por los derechos de libertad inviolables (Bobbio, 2012: 107). Esta limitación de carácter material no solo trata de evitar el retorno a una dictadura que se apropie del poder de hacer normas y que pretenda, así, legitimar su pretensión de obediencia, sino también de cerrar el paso a una concepción jacobina o decisionista-totalitaria de la democracia, que haga de la decisión mayoritaria la suprema y todopoderosa instancia del Estado, absoluta y sin límites (García de Enterría, 1984: 20). El ideal de Estado de derecho fue reconceptualizado tras los horrores de la Segunda Guerra Mundial (Weiler, 2016: 316), desembocando en las concepciones sustantivas o thick versions, cuyos defensores afirman que el Estado de derecho puramente formal es una carcasa vacía si no incluye límites sustantivos (Martín Rodríguez, 2016: 160-164). El constitucionalismo también se vio afectado por este cambio de paradigma, surgiendo como respuesta su vertiente material, según la cual solo aquellas constituciones que cumplen con la democracia representativa, la separación de poderes y el respeto y garantía de los derechos fundamentales pueden ser consideradas como «constituciones reales» (Schütze, 2019: 54).

A lo largo de este proceso de adaptación, la vis expansiva del Estado de derecho provocó que nuevos contenidos quedaran incluidos en él. Este proceso evolutivo del que ha sido objeto el Estado de derecho no ha sido pacífico, sino que ha estado condicionado por las transformaciones producidas a lo largo del tiempo y, por ello, debe ser estudiado teniendo en cuenta el contexto histórico, cultural y sociológico en el que se incardina (Selznick, 1999: 21). La naturaleza conflictiva de la evolución del Estado de derecho se ve claramente reflejada en Hungría y Polonia, donde tuvo que producirse la caída del régimen de la URSS para que fuera instaurado el Estado de derecho; e incluso entonces la evolución no fue natural, sino que la implantación de este concepto «extraño» para la cultura jurídica de ambos Estados (Steiner, 2019: 136), se produjo porque formaba parte de los Criterios de Copenhague y, por tanto, era uno de los requisitos que debían cumplir para acceder a los beneficios económicos derivados de la adhesión a la Unión Europea. 
Podemos afirmar, con carácter general, que el Estado de derecho se fundamenta en los siguientes elementos: el imperio de la ley, la separación de poderes ${ }^{4}$, la legalidad de la Administración y la garantía jurídico-formal y efectiva realización de los derechos y libertades fundamentales (Díaz García, 1988: 31). Mientras que en la versión débil del Estado de derecho el respeto y la garantía de los derechos fundamentales dependía de su juridificación, en la versión robusta la validez de las leyes queda subordinada al respeto de los derechos fundamentales constitucionalmente reconocidos (Uprimny Yepes, 2013-2014: 172), de modo que el Tribunal Constitucional se convierte en garante de la pervivencia y perfeccionamiento del Estado de derecho (Lucas Verdú, 1983).

Por tanto, será en la concepción material, amplia o robusta del Estado de derecho donde encuentra cabida nuestro objeto de estudio: el derecho fundamental de igualdad. Entendemos con el profesor Baño León que «si bien la idea de igualdad es filosófica e históricamente muy anterior al advenimiento del Estado de derecho, jurídicamente su prosperidad no se produce hasta que el principio del Estado de derecho se asienta en el primer constitucionalismo» (Baño León, 1987: 179).

Aunque en un principio los derechos fundamentales no constituían uno de los pilares basilares de la Unión Europea, en el nuevo espacio jurídico europeo se han convertido en la seña de identidad, hasta el punto de que su protección en el seno de la UE ha sido el más visible caballo de batalla para materializar la vigencia del Estado de derecho, comenzando con la actuación pretoriana del TJUE en la saga Solange y culminando con el artículo 6 TUE (Martín y Pérez de Nanclares, 2019: 128 y 135).

La Comisión Europea afirmó en su COM (2014) 158 final que la igualdad es uno de los principios que conforman el Estado de derecho 5 . La gravedad de la vulneración del Estado de derecho en los Estados miembros proviene, precisamente, de la construcción de la Unión Europea sobre el principio de confianza mutua, de modo que su vulneración a nivel nacional se traduce, automáticamente, en un deficiente Estado de derecho de la Unión y provoca la negación de facto de los llamados derechos europeos (Bogdandy y Ioannidis, 2014: 27). Ante la vulneración del Estado de derecho en Hungría

4 La separación de poderes ha sido señalada como una de las características básicas del Estado de derecho por el Tribunal Constitucional español en su Sentencia 108/1986, de 29 de julio, FJ 6; y por el TJUE, en la Sentencia de 10 de noviembre de 2016, C-477/16 PPU (Ruslanas Kovalkovas).

5 Comunicación de la Comisión al Parlamento Europeo y al Consejo, de 11 de marzo de 2014, «Un nuevo marco de la UE para reforzar el Estado de derecho». 
y Polonia, el Consejo ha activado el procedimiento del artículo 7.1 TUE, cuyo principal objetivo es constatar la existencia de un riesgo claro de violación grave por parte de un Estado miembro de los valores del art. $2 \mathrm{TUE}^{6}$. La falta de "coraje político" ha provocado que sendos procedimientos sigan aún en fase de audiencia (Cortés Martín, 2020: 480), por lo que aún no se ha producido la constatación, pero la mera activación del mecanismo ha servido como base para que el TJUE convierta el antes inquebrantable principio de confianza mutua en una presunción iuris tantum que puede ser destruida si se aportan evidencias suficientes que demuestren la vulneración del Estado de derecho ${ }^{7}$.

El Estado de derecho, además de actuar como límite para los poderes públicos, debe constituirse como fuente de nuevas posibilidades (Corstens, 2017: 16), encontrando la justa medida entre la constricción y la cesión de poder para que el poder público pueda cumplir con sus cometidos. Esta afirmación gana relevancia con el surgimiento del Estado social de derecho y la consiguiente aparición de la naturaleza prestacional del Estado, pues al establecer límites a la discrecionalidad del poder público, la constitución también puede servir para aumentar la capacidad de movilización de recursos del Estado y revertir en la realización del interés general (Krygier, 2018: 48).

La interdicción de cualquier tipo de discriminación por motivo de orientación sexual o identidad de género es uno de los aspectos que deben ser garantizados por el Estado, sobre la base de la igualdad como derecho fundamental subjetivo (Baño León, 1987: 183) y como una de las prohibiciones de discriminación especiales ${ }^{8}$. No basta la proclamación formal de igualdad

6 En el caso de Polonia fue activado a propuesta de la Comisión Europea en su Recomendación (UE) 2018/103, mientras que en el caso de Hungría la negativa de la Comisión para activar este mecanismo provocó que fuera el Parlamento Europeo quien lo hiciera, en su Resolución 2017/2131(INL).

7 El TJUE llegó a esta conclusión al responder una cuestión prejudicial planteada por el Tribunal Superior de Irlanda al hilo de una orden de detención europea formulada por Polonia, en la Sentencia del Tribunal de Justicia (Gran Sala) de 25 de julio de 2018, en el asunto C-216/18 PPU, Minister for Justice and Equality (deficiencias del sistema judicial). Señaló que las recientes reformas realizadas en dicho Estado y la iniciación del procedimiento del art. 7.1 TUE pueden servir a los órganos jurisdiccionales nacionales a la hora de ponderar si en Polonia se respetarían los derechos de la persona sobre la que verse euroorden, haciendo hincapié en la falta de independencia del poder judicial en Polonia (Krzywoń, 2020: 93).

8 En estos casos la conducta discriminatoria tiene trae causa de una generalización o estereotipo negativo, un prejuicio ligado a un grupo que se adjudica a una persona tan solo por pertenecer a él y que, en general, proviene de rasgos inmodificables que quedan fuera de su poder de disposición (Rey Martínez, 2017: 136). 
y del principio de no discriminación, sino que el marco del Estado social de derecho incluye el mandato a los poderes públicos de promover la igualdad real mediante mecanismos de garantía y protección que eviten la discriminación y palien la situación de desventaja y minusvaloración que tradicionalmente han sufrido determinados colectivos (Criado de Diego, 2011: 16) y, entre ellos, la comunidad LGTBI ${ }^{9}$.

Sin embargo, estos derechos no son propios de la concepción débil del Estado de derecho, como núcleo esencial aceptado por la mayoría de Estados, sino que se predica únicamente respecto de sociedades y Estados concretos, por la naturaleza particularista inherente a las formas de asociación (Selznick, 1999: 32). Por tanto, el reto para la UE consiste en implantar los estándares de protección de los derechos LGTBI en aquellos Estados miembros cuyas tradiciones constitucionales no los conciban y, como en el caso que luego veremos, restaurarlos en aquellos se ha producido una involución: al suprimir derechos ya reconocidos en los que el Estado en cuestión no solo estaría incumpliendo su mandato interno de promover las condiciones necesarias para garantizar el respeto de los derechos fundamentales, sino que además estaría incumpliendo sus obligaciones derivadas del derecho internacional ${ }^{10}$.

Hablamos de reto porque, aunque los derechos humanos forman parte de los valores fundamentales de la Unión (art. 2 TUE), la intervención de esta queda restringida al ámbito del derecho de la UE, como prevé el art. 51 CDFUE. Tradicionalmente el TJUE ha adoptado una actitud cauta a la hora de proteger derechos fundamentales que quedaban totalmente bajo el amparo de la autonomía nacional (Danwitz, 2014: 1339). La interdicción de la discriminación por motivos de orientación sexual e identidad de género no estaba incluida en un principio en el catálogo europeo de derechos, por lo que el TJUE comenzó a introducirlos a través de diversas técnicas. Utilizó una

9 Podemos señalar, por ejemplo, las medidas de acción positiva, analizadas en las SSTC 128/1987, de 16 de julio, FJ 7. ${ }^{\circ}$; y 12/2008, de 29 de enero, FJ 2. ${ }^{\circ}$.

$10 \mathrm{El}$ art. 1 DUDH se refiere a la concepción liberal de la igualdad y el art. 2 DUDH se refiere a la interdicción de cualquier tipo de discriminación. Aunque no se refiera expresamente a la orientación sexual ni a la identidad de género, quedan incluidos en la denominada cláusula abierta (cualquier otra condición). El Comité de Derechos Humanos de NNUU afirmó en el 13. ${ }^{\circ}$ Periodo de Sesiones (observación general 3) que «considera necesario señalar a la atención de los Estados partes el hecho de que la obligación prevista en el Pacto no se limita al respeto de los derechos humanos, sino que los Estados partes se han comprometido también a garantizar el goce de esos derechos por todas las personas sometidas a su jurisdicción. Este aspecto exige que los Estados partes realicen actividades concretas para que las personas puedan disfrutar de sus derechos». 
interpretación amplia de la discriminación por razón de género en $P$. contra S. y Cornwall County Council ${ }^{11}$, pero siguió mostrando la cautela que señalábamos en Lisa Jacqueline Grant contra South-West Trains ${ }^{12}$, donde afirmó que «una discriminación basada en la inclinación sexual no entraba dentro del ámbito de aplicación del derecho comunitario» (Manzano Barragán, 2009: 165-173). Gracias a la Directiva 2000/78/EC de Igualdad de Trato en el Empleo y la Ocupación y la firma del nuevo Tratado de Lisboa, el TJUE pudo cambiar de tendencia: en el asunto Asociația ACCEPT/Consiliul Național pentru Combaterea Discriminării ${ }^{13}$ señaló que si la parte demandante proporciona indicios suficientes para "presumir la existencia de discriminación» la carga de la prueba corresponderá a la parte demandada (Díaz Lafuente, 2019); y en el asunto Bevándorlási és Állampolgársági Hivatal ${ }^{14}$, donde prohibió realizar informes psicológicos a las personas LGTBI solicitantes de protección internacional porque constituye una injerencia en su derecho a la vida privada, desproporcionada en relación con el objeto perseguido (Arroyo Gil, 2019: 14).

Para que la UE intervenga en uno de sus Estados miembros debe constatarse la violación efectiva de los principios políticos comunes, la conducta del Gobierno y las reformas producidas deben tener carácter sistémico ${ }^{15}$ y debe circunscribirse a la ejecución de compromisos que fueron adquiridos voluntariamente en el pasado. Se configura como la ultima ratio, reservada para aquellos casos en que no se puede confiar en la resolución de los problemas en el ámbito nacional (Müller, 2014: 150-151).

Existen varios mecanismos con los que la Unión puede intervenir para garantizar el cumplimiento del Estado de derecho en sus Estados miembros. Los principales son el art. 7 TUE, el nuevo marco de la Comisión para reforzar el Estado de derecho y el procedimiento de infracción del art. 258. Si realizamos un breve repaso, observamos que el art. 7 TUE se configura como un mecanismo de naturaleza política (Šišková, 2019: 124) y está bloqueado por la unanimidad requerida en su apartado segundo, por lo que en la práctica es imposible que se impongan sanciones por esta vía ${ }^{16}$. El nuevo marco tiene

11 Sentencia del Tribunal de Justicia, de 30 de abril de 1996, en el asunto C-13/94. Sentencia del Tribunal de Justicia, de 17 de febrero de 1998, en el asunto C-249/96. Sentencia del Tribunal de Justicia, de 25 de abril de 2013, en el asunto C-81/12. Sentencia del Tribunal de Justicia, de 25 de enero de 2018, en el asunto C-473/16. El término sistémico es desarrollado en profundidad por Bogdandy y Ioannidis (2014). Aunque el apartado primero del art. 7 TUE requiere para la constatación una mayoría de cuatro quintos en el seno del Consejo, para la efectiva imposición de las sanciones a las que se refiere el apartado tercero es necesario alcanzar la unanimidad en el Consejo Europeo exigida por el apartado segundo y, por ello, los efectos coercitivos de este instrumento quedan (de facto) bloqueados por esta sinergia. 
una naturaleza dialógica (Crabit y Bel, 2019: 202) y ha mostrado su falta de efectividad tras años de infructuoso diálogo entre la Unión Europea y Polonia (Šišková, 2019: 127). El procedimiento tradicional de infracción recogido en el art. 258 TFUE, aunque puede suponer un triunfo judicial, carece de eficacia en aquellos supuestos en los que la voluntad expresa del Estado miembro es vulnerar el derecho de la Unión Europea ${ }^{17}$, salvo que dicho procedimiento venga acompañado de la aprobación de medidas cautelares, cuya efectividad ha quedado demostrada en los procedimientos iniciados contra Polonia, para evitar que las autoridades nacionales puedan efectuar un cumplimiento «creativo» de los fallos del TJUE, como ocurrió en el caso de Hungría (Cortés Martín, 2020: 499).

Para que intervenga la UE en uno de sus Estados miembros por la vulneración de la igualdad, al tratarse de un derecho fundamental, entendemos que la vía más adecuada es la utilización del procedimiento de infracción del art. 258 TFUE. Esta vía ya ha sido utilizada por el TJUE para determinar en el asunto C-192/18 (sentencia de 5 de noviembre de 2019) que Polonia «ha incumplido las obligaciones que le incumben [...] relativa a la aplicación del principio de igualdad de oportunidades e igualdad de trato entre hombres y mujeres en asuntos de empleo y ocupación, al establecer [...] edad de jubilación diferente para las mujeres y los hombres que desempeñan el cargo de juez en los tribunales ordinarios y en el Sąd Najwyższy (Tribunal Supremo) o el cargo de fiscal». Sin embargo, esta afirmación proviene de la infracción de una disposición concreta del derecho de la UE y, por tanto, no sería aplicable por vulneración del derecho fundamental de igualdad recogido en la CDFUE. Por tanto, lo ideal sería avanzar un paso más y que los derechos fundamentales, como uno de los valores en los que se fundamenta la Unión, puedan servir para determinar si uno de sus miembros vulnera el Estado de derecho, incluso en aquellas situaciones puramente internas —en las que la Unión carece de competencias- en línea con la doctrina Reverse

17 Por las dificultades que surgen a la hora de ejecución de las sentencias del TJUE, conforme a lo dispuesto en el art. 260 TFUE (Jack, 2013). El procedimiento de infracción del art. 258 TFUE tiene carácter individual y se circunscribe a la vulneración del derecho de la UE de una medida nacional concreta, por lo que a pesar de que el TJUE condene a un Estado miembro, este último podrá evadir el control por la vía del 260 TFUE retirando la norma concreta y sustituyéndola por otra en el mismo sentido, pues para controlar la nueva disposición sería necesario iniciar otro procedimiento de infracción. 
Solange (Bogdandy y Smrkolj, 2012: 491) ${ }^{18}$. Debemos tener en cuenta, sin embargo, que el Protocolo n. ${ }^{\circ} 30$ sobre la aplicación de la CDFUE a Polonia y al Reino Unido establece que en ambos Estados esta no puede ser utilizada por el TJUE ni por los tribunales nacionales para determinar la validez de las normas legales, salvo en la medida en que los derechos de la Carta hayan sido recogidos por el derecho nacional. En consecuencia, la CDFUE únicamente puede ser utilizada por la Unión para determinar la invalidez de normas nacionales que la contravengan respecto de Hungría, pero no respecto de Polonia, donde la UE tendría que recurrir al resto de instrumentos con los que cuenta para garantizar el Estado de derecho.

En el marco de la UE existen varios documentos sobre los derechos LGTBI, pero el que verdaderamente goza de fuerza vinculante es el art. 21.1 CDFUE, que prohíbe la discriminación por razón de orientación sexual. Aunque no se refiera expresamente a las personas intersexuales, su dignidad, como la de cualquier otra persona, indudablemente es inviolable y merecedora de respeto y protección (Arroyo Gil, 2020: 46), por lo que también quedaría prohibida la discriminación por motivo de identidad de género ${ }^{19}$. Aunque la Carta adquirió el estatus de derecho originario de la Unión con el Tratado de Lisboa, el art. 51.1 CDFUE restringe su fuerza vinculante cuando los Estados miembros actúan fuera del ámbito del derecho de la Unión (Claes y Bonelli, 2019: 280).

En el ámbito del Consejo de Europa, como señala la CM/Rec(2010)5, la orientación sexual y la identidad de género no están expresamente protegidas por el art. $14 \mathrm{CEDH}$ y su Protocolo n. ${ }^{\circ} 12$, pero al igual que ocurre en la UE se considera que la lista de motivos de discriminación prohibidos no es de carácter cerrado y, por tanto, los derechos LGTBI quedan incluidos bajo su manto protector ${ }^{20}$. En este sentido se ha pronunciado el TEDH en Salgueiro da Silva Mouta c. Portugal (1999) y en Karner c. Austria (2003), así como en

18 Podría ser articulado utilizando la misma argumentación del TJUE en Sentencia de 11 de abril de 2019 (Comisión contra Polonia, C-619/18), en el que la UE condenó a Polonia por vulnerar el Estado de derecho de forma indirecta, a través de uno de sus componentes: la tutela judicial efectiva del art. 19.1 TUE en conexión con la falta de independencia judicial. Respecto de los derechos fundamentales, el TJUE tendría que encontrar en el derecho originario un precepto de similares características que permitiera una condena indirecta por vulneración de los derechos fundamentales.

19 El TJUE lo admitió por primera vez en P. c. S. y Cornwall County Council (Díaz Lafuente, 2019: 84).

20 La jurisprudencia del TEDH ha servido para que los Estados vayan incorporando de forma paulatina en sus ordenamientos jurídicos los derechos LGTBI, como en el caso de España, que por su influencia acabó reconociendo la constitucionalidad del 
Schlumpf contra Suiza (2012), donde señaló (\$115) que «en estos casos, por tratarse de una de las cuestiones más íntimas de la vida privada, la amplitud del margen de apreciación de los Estados es reducida, y deben existir motivos de especial gravedad para justificar la injerencia de la autoridad pública», por lo que deben extremarse las precauciones a la hora de realizar el test de proporcionalidad. La CM/Rec(2010)5 subraya la relevancia — negativa - de aquellas declaraciones homófobas que provienen de figuras públicas, por su especial capacidad de persuasión, pues influyen negativamente en la ciudadanía y promueven la intolerancia.

\section{VULNERACIÓN DE DERECHOS LGTBI EN TIEMPOS DE PANDEMIA}

En este apartado expondremos el contexto iliberal en el que se ha producido la vulneración de los derechos LGTBI; el curso actual de las reformas que se han producido en Hungría y Polonia en este sentido, teniendo en cuenta la ampliación de los poderes del poder ejecutivo como consecuencia de la crisis de la COVID-19; y, finalmente, analizaremos la respuesta de las instituciones de la Unión Europea.

\section{CONTEXTO ILIBERAL}

Tradicionalmente, la UE se ha relacionado con sus Estados miembros mediante el diálogo (Uitz, 2019: 8) y, si esto no era suficiente, recurría al procedimiento de infracción contenido en el art. 258 TFUE. Sin embargo, en los últimos años los partidos políticos euroescépticos se han alzado con el poder en Hungría (Fidesz) y en Polonia (PiS) ${ }^{21}$, adoptando una agenda política repleta de reformas iliberales, posible gracias a la mayoría de la que gozan en sus respectivos parlamentos. En estos casos, la solución tradicional (dialógica) de la Unión no es suficiente, pues las vulneraciones no son accidentales, sino que suponen la materialización de la ideología política de los partidos que allí gobiernan. Son muchas las reformas realizadas por Fidesz y PiS para erosionar el Estado de derecho, pero estas no han adoptado

matrimonio entre personas del mismo sexo en la STC 198/2012, de 6 de noviembre, FJ 9 (Gibaja Cabrero, 2014: 305-306).

21 Fidesz (Fiatal Demokraták Szövetsége, Alianza de Jóvenes Demócratas), de ideología conservadora nacionalista y defensor de un populismo de extrema derecha. PiS (Prawo i Sprawiedliwość, Ley y Justicia) partido de ultraderecha, caracterizado por una ideología católica y nacionalista. 
la forma del iliberalismo tradicional, sino que se acercan más a los denominados autoritarismos sofisticados (Morgenbesser, 2020), a través de lo que algunos denominan constitutional coup (Scheppele, 2018: 449), un golpe constitucional en que el partido político que ha conseguido gobernar en solitario gracias a la mayoría obtenida en las elecciones utiliza a su favor los procedimientos legislativos y la propia Constitución para alcanzar sus propios objetivos. Esto resulta preocupante si tenemos en cuenta el contexto en el que se produce, pues en el caso de Hungría y Polonia se ha eliminado previamente el sistema de pesos y contrapesos y, por este motivo, no hay forma de controlar que estas reformas cumplen los cánones de constitucionalidad nacionales o el derecho internacional de derechos humanos. Podemos afirmar que los gobiernos de Hungría y Polonia han conseguido secuestrar la democracia, utilizando el ordenamiento jurídico-constitucional a su favor, pues se han servido de los mecanismos proporcionados por el derecho para actuar como caballo de Troya y acabar desde dentro con los controles propios del constitucionalismo. Como prueba de ello, en los procedimientos de infracción que la Comisión ha iniciado frente a sendos Estados y en las recomendaciones derivadas de la utilización del nuevo marco respecto de Polonia, sendos Gobiernos han esgrimido argumentos de derecho comparado, señalando la presencia de este tipo de reformas en otros Estados miembros ${ }^{22}$. Es difícil encontrar elementos de prueba suficientes como para determinar que las reformas, aunque son admisibles en otros Estados miembros y conserven la apariencia de legalidad (elementos formales), en realidad tratan de minar el contenido material del Estado de derecho; pero la respuesta se halla en la consideración del contexto político-constitucional existente en ambos Estados.

La tendencia seguida por los gobiernos iliberales consiste en la inutilización del principio de separación de poderes — sistema de pesos y contrapesos ${ }^{23}$ para luego poder acometer reformas destinadas a la petrificación del contexto político contemporáneo, mediante modificaciones del sistema electoral para conservar el poder y, en caso de no conseguirlo, reformas del procedimiento legislativo que implantan mayorías imposibles de conseguir para la oposición en la situación actual. Además, presentan a la Unión como el enemigo al que

22 En este sentido se pronunció, por ejemplo, la opinión minoritaria respecto del documento que sirvió para que el Parlamento Europeo iniciara el procedimiento del art. 7.1 TUE respecto de Hungría, conocido como Informe Sargentini 2017/2131(INL), al señalar que «el informe se basa en la premisa de que Hungría no tiene derecho a adoptar decisiones que otros Estados miembros de la Unión Europea han adoptado». Los principales objetivos institucionales fueron el Tribunal Constitucional, el Tribunal Supremo y el poder judicial ordinario. 
se refería Schmitt (Campoy Cervera, 2017: 64-71), proclamándose valedores de los intereses nacionales frente a una UE que solo trata de arrebatarles su recién recuperada soberanía y, por tanto, aumentando sus réditos electorales ${ }^{24}$.

$\mathrm{Al}$ principio el contexto internacional estaba dividido en relación con las reformas. Por un lado, fueron alabadas porque implantaban la verdadera soberanía parlamentaria ${ }^{25}$, ignorando así el control del resto de poderes del Estado, en la línea de lo propuesto por Mark Tushnet y Ran Hirschl ${ }^{26}$, mientras que algunas voces críticas alertaban del peligro que suponía asegurar los intereses de una sola fuerza política sin la existencia del sistema constitucional de pesos y contrapesos (Tóth, 2017: 388). En los últimos años la mayoría de la doctrina y las instituciones de la UE han adquirido consciencia del verdadero riesgo que suponen los Gobiernos iliberales para el conjunto de Estados miembros y el Estado de derecho se encuentra en el punto de mira de los debates de la Unión. En este contexto, la vulneración de los derechos LGTBI constituye el punto álgido de unas reformas que cada vez recuerdan más a los horrores que vivimos el siglo pasado.

Pese a las reformas iliberales, parte de la doctrina sigue considerando que Hungría y Polonia pertenecen al grupo de las democracias constitucionales, aun en el sentido débil o formal del término (Drinóczi y Bién-Kacala, 2021: 31). Sin embargo, un reciente estudio del V-Dem Institute califica a Hungría como el primer Estado miembro de la UE en ser considerado un "régimen electoral autoritario» (Pech y Grogan, 2020: 45) ${ }^{27}$.

Finalmente, debemos hacer referencia a un hecho que extralimita la esfera puramente jurídica, pero puede tener grandes efectos sobre ella en la práctica. A raíz de la reciente reforma interna del Partido Popular Europeo (PPE) para permitir la suspensión no solo de miembros del Parlamento Europeo, sino de

24 La capacidad de ambos Estados para movilizar a la ciudadanía utilizando este tipo de argumentos queda demostrada con los resultados electorales obtenidos por Fidesz y PiS. Hungría y Polonia comparten un bagaje histórico-político de dominación extranjera y, como consecuencia, la soberanía nacional es un bien muy preciado que se convierte en una potente arma en manos de los partidos euroescépticos.

Por ejemplo, Jaime Mayor Oreja (entonces ministro de Interior de España) intervino en el debate del Informe Tavares señalando que el Parlamento Europeo no estaba siendo imparcial y que se trataba de una decisión del «ala izquierda" que pondría a Hungría bajo custodia política (Pech y Grogan, 2020: 56).

26 Gábor Attila Tóth se refiere a Taking the Constitution away from the Courts (Tushnet) y a Towards juristocracy: The origins and consequences of the New Constitutionalism (Hirschl).

27 Autocratization Surges, Resistance Grows: Democracy Report 2020 (https://www.v-dem. net/en/). 
grupos políticos al completo, Viktor Orbán ha decidido retirar a Fidesz del PPE. Tras ello, se han producido dos reacciones muy dispares en el contexto internacional: hay quienes sienten alivio porque la retirada de Fidesz supone eliminar un obstáculo para el PPE en su avance hacia objetivos más europeístas ${ }^{28}$; pero, desde nuestro punto de vista, también puede desembocar en un escenario muy distinto, como es la desintegración del último baluarte de contención para las reformas iliberales en Hungría. Si Fidesz logra crear un nuevo grupo político de ultraderecha en el seno del Parlamento Europeo ${ }^{29}$, no solo desaparecería el freno que hasta ahora suponía su pertenencia al PPE, haciendo desaparecer la necesidad de mantener la fachada de legalidad que tanto tiempo llevan manteniendo, sino que, además, supondría la creación de un nuevo grupo político en el Parlamento Europeo con unos valores diametralmente opuestos a los valores fundamentales de la propia UE y, eventualmente, podría implicar la aceleración de la degeneración iliberal que Hungría viene sufriendo desde 2010.

\section{LA RESPUESTA DE HUNGRÍA Y POLONIA A LA COVID-1930}

En Hungría y Polonia nos encontramos, al igual que sucede respecto de las reformas iliberales que han llevado a cabo, dos estrategias que persiguen un único objetivo: aprovechar la respuesta gubernamental a la crisis de la COVID-19 para conseguir una (aún) mayor concentración del poder en manos del Ejecutivo. En Hungría el Gobierno de Fidesz ha recurrido a uno de los mecanismos constitucionales de emergencia previstos por la Ley Fundamental de 2011, concretamente la declaración del estado de peligro que tuvo lugar el 11 de marzo de $2020^{31}$; mientras que en Polonia el Gobierno de PiS decidió no utilizar los mecanismos de emergencia previstos por la Constitución de 1997, sino que recurrió al denominado estado (legal) de epidemia,

28 Véase: https://euobserver.com/political/151119 (última consulta: 12 de marzo de 2020).

29 Fidesz ha iniciado negociaciones con La Liga de Matteo Salvini en Italia, pero es previsible que busque aliados en países como Polonia (PiS) o Francia (Frente Nacional). Véase: https://cutt.ly/JbK30Rm.

30 Realizaremos aquí una aproximación a la respuesta de ambos Estados a la crisis de la COVID-19. Para un análisis más profundo pueden consultarse nuestro artículo en el Anuario de la Facultad de Derecho de la Universidad de Extremadura (Barroso Márquez, 2020b) respecto de Polonia, y nuestra contribución a la obra La Constitución en tiempos de pandemia (Barroso Márquez, 2021) respecto de Hungría.

31 Decreto del Gobierno 40/2020 (http://njt.hu/translated/doc/J2020R0040K 20200311_FIN.pdf, última consulta: 7 de octubre de 2020). Este documento solo recoge las competencias adquiridas por el primer ministro a raíz del estado de peligro, tal y como especifica la Ley Fundamental en su art. 53. 
declarado el 20 de marzo de $2020^{32}$. La divergencia de la actuación de Fidesz y PiS frente a la crisis de la COVID-19 hunde sus raíces en el contexto previo de ambos Estados.

En Hungría el Parlamento tiene el monopolio de la producción legislativa y, como consecuencia, la declaración del estado de peligro se presentó como la única posibilidad de que el Gobierno de Orbán pudiera gobernar por decreto, teniendo en cuenta, además, que carecía de limitación temporal alguna, debido a que el art. 8 únicamente señalaba que la decisión que pusiera fin al estado de emergencia sería tomada por el Parlamento cuando acabara la emergencia ${ }^{33}$. El 30 de marzo de 2020 -tras varios obstáculos (Barroso Márquez, 2021: 268) — fue adoptada la Ley sobre Protección contra el Coronavirus $^{34}$. Aunque el 18 junio de 2020 finalizó el estado de peligro, se declaró el «estado (legal) de emergencia sanitaria pública» hasta el 18 de diciembre de $2020^{35}$, que mantenía en vigor las prerrogativas adquiridas por el Gobierno de Fidesz gracias al estado de peligro y, simultáneamente, desechaba el shielding effect o efecto protector inherente a los regímenes de emergencia constitucionalmente previstos (Greene, 2020).

En el caso de Polonia, por el contrario, el Gobierno de PiS descartó la activación de los mecanismos constitucionales de emergencia por dos razones: en primer lugar, porque la declaración del estado de desastre natural ${ }^{36}$ no habría facultado al Poder Ejecutivo para gobernar por decreto; y, en segundo lugar, porque su activación supondría la suspensión de la fecha de las elecciones presidenciales y el surgimiento de la obligación de compensación por parte del Estado, como prevé el art. 228.7 de la Constitución. Este empeño de PiS por

32 Mediante el Reglamento de 20 de mayo de 2020, del ministro de Salud, que introduce el estado de epidemia dentro de los límites de la República de Polonia.

33 Más grave aún resulta esta precisión si tenemos en cuenta que el Parlamento húngaro es controlado por una amplia mayoría de Fidesz, el mismo partido al que pertenece el Gobierno de Orbán, beneficiario absoluto de las prerrogativas derivadas de la utilización de los poderes de emergencia en Hungría.

34 La propuesta inicial tuvo lugar el día 20 de marzo de 2020. Documento T/9790 (https://www.parlament.hu/irom41/09790/09790.pdf, última consulta: 7 de octubre de 2020).

35 Mediante la Ley en Respuesta a las Emergencias (LVII de 17 de junio de 2020), que derogó la anterior Coronavirus Act, y la Ley sobre los Aspectos Transitorios de la Emergencia y la Preparación Epidemiológica (LVIII, de 17 de junio de 2020), disponibles en: https://cutt.ly/QbK800c (última consulta el 7 de octubre de 2020).

36 Este régimen de emergencia, previsto por el art. 232 de la Constitución de 1997, es el que mejor se corresponde con las concretas circunstancias de la crisis pandémica causada por la COVID-19. 
mantener la fecha de las elecciones presidenciales, inicialmente fijadas el 10 de mayo de 2020, se debía a la desigualdad de oportunidades nacida a raíz de las medidas anticoronavirus, ya que Andrzej Duda, candidato de PiS para los comicios y entonces presidente, fue el único que en aquel momento pudo llevar a cabo su campaña electoral en condiciones normales por su posición institucional. Asimismo, una de las reformas afectó a las normas de funcionamiento del Parlamento, instaurando la posibilidad de asistir de forma telemática (Serowaniec y Witkowski, 2020) para tratar de reformar el Código Electoral y hacer posible que las elecciones presidenciales tuvieran lugar por correo. La propuesta no prosperó, pero PiS finalmente consiguió aprobar otra que facultaba al presidente de la Cámara de los Diputados para posponer la fecha de las elecciones por la pandemia ${ }^{37}$. El 11 de mayo presentó una ley que, con tres lecturas en un mismo día, fue aprobada al día siguiente y derogó la normativa anterior, sustituyendo la obligación de voto postal por la opción de voto postal y fijando los días 28 de junio y 12 de julio como las nuevas fechas para las dos vueltas de las elecciones presidenciales ${ }^{38}$.

Si nos remitimos a las palabras de Bárd y Carrera (2020: 2), las pandemias no hacen nacer las «autocracias», sino que revelan la «verdadera naturaleza» (true colours) de los regímenes de este tipo. En el caso de Hungría y Polonia, por tanto, las medidas adoptadas para hacer frente a la COVID-19 pueden servir como ejemplo de aceleración de la deriva iliberal que ambos Estados vienen sufriendo desde hace casi una década, pero no pueden ser contempladas como un fenómeno aislado o ex novo. Esta aceleración, como dijimos, puede traer como consecuencia una mayor velocidad de la degeneración del sistema de protección de los derechos fundamentales de las minorías en Hungría y Polonia.

\section{MEDIDAS ANTI-LGTBI EN POLONIA}

En primer lugar, debemos tener en cuenta que Polonia es uno de los Estados miembros en los que la Iglesia católica tiene mayor peso ${ }^{39}$. En

37 El 8 de mayo, tan solo dos días antes de la fecha inicialmente fijada para las elecciones presidenciales.

38 El art. 127 de la Constitución (apartados 4, 5 y 6) establece que si en la primera vuelta ninguno de los candidatos obtiene la mitad de los votos válidamente emitidos, debe celebrarse una segunda vuelta en la que solo participarán los dos candidatos más votados de la primera y que, en esta última, el candidato que obtenga el mayor número de votos será elegido presidente de la República.

39 Según un estudio del Pew Research Center, el $86 \%$ de la población polaca manifiesta tener creencias religiosas, por lo que la influencia de la religión es mucho mayor que 
los últimos años se han introducido numerosas restricciones sobre los derechos de la mujer, como la reciente prohibición del aborto eugenésico (Barroso Márquez, 2020b: 56), pero también las controversias sobre la ideología de género, el rechazo de la educación sexual y la violación de los derechos LGTBI, entre otros (Gradskova et al., 2020: 366). El informe de la Agencia de la Unión Europea por los Derechos Fundamentales (FRA) nos muestra los siguientes datos sobre Polonia: el $68 \%$ de los encuestados considera que se ha incrementado la intolerancia; el $66 \%$ considera que también ha aumentado con carácter general la violencia contra el colectivo LGTBI; el 79\% evita acudir a ciertos sitios para evitar la violencia; el nivel de satisfacción con la calidad de vida es casi dos puntos inferior que la media general y, por último, es el lugar donde se produce el mayor número de ataques sexuales motivados por la condición LGTBI de la víctima, un 15\% (FRA, 2020: 12, 25, 28 y 39). La siguiente declaración, recogida en este informe, ejemplifica la situación del colectivo LGTBI en Polonia:

La atmósfera general en Polonia ha cambiado drásticamente en los últimos años en términos de percepción LGTB en el entorno. Las autoridades públicas se enorgullecen de su intolerancia declarando cada vez más áreas del país libres de LGTBI. No confío en la policía ni en los tribunales respecto de estos asuntos. Estoy más que seguro de en el caso de tener algún problema relacionado con mi orientación, sería tratado con asco, humillado e ignorado sistémicamente (Polonia, hombre gay, 39) (FRA, 2020: 13).

Estimamos relevante esta declaración porque no solo se refiere a la problemática de la vulneración de los derechos fundamentales, sino también a la inexistencia de un sistema efectivo de protección de estos derechos fundamentales como consecuencia de la reforma del Poder Judicial que se ha producido en Polonia. Aquellos Estados que cuentan con un Poder Judicial independiente solucionan la vulneración de los derechos fundamentales a través del cauce ordinario, la protección judicial; pero esto es imposible en un Estado en el que el Poder Ejecutivo controla de facto al Judicial ${ }^{40}$, y este es precisamente el motivo por el que el colectivo LGTBI ya no puede confiar en la justicia polaca.

En los informes de ILGA-Europe (ILGA-Europe, 2020 y 2021) encontramos varios datos sobre Polonia que son ilustrativos para nuestro objeto de

en otros Estados, como Hungría, donde la cifra se reduce a un $59 \%$ (https://cutt.ly/ fbK4jFk, última consulta: 27 de junio de 2020).

40 Para profundizar sobre este aspecto, consultar el capítulo 4 de la obra de Sadurski (2019: 96-131). 
investigación. En marzo, Jarosław Kaczyński (líder de PiS) afirmó que el apoyo al colectivo LGTBI por parte del alcalde de Varsovia era un ataque a los niños y las familias, utilizando una retórica similar a la de la Iglesia y otros círculos conservadores. Hasta ahora, casi cien ciudades - un tercio del territorio de Polonia- se han declarado "zonas libres de ideología LGTBI», e incluso en la ciudad de Lublin se galardonó a los policías que se oponían a la ideología LGTBI. El 17 de julio de 2019, el periódico conservador Gazeta Polska lanzó una campaña regalando pegatinas con el lema «LGBT-free zone» en su edición semanal, con un diseño que consistía en una cruz negra sobre la bandera arcoíris, utilizando como argumento que su objetivo no era incitar al odio, sino demostrar que serían objeto de censura por reflejar la postura anti-LGTBI. Sin embargo, el Gobierno de PiS afirmó que no los sancionaría "para proteger la libertad de expresión". Esta campaña fue condenada por varias figuras públicas, como el embajador de los Estados Unidos y el alcalde de Varsovia, que llegó a compararla con la era nazi. El caso fue llevado ante el Tribunal Regional de Varsovia, que ordenó la retirada provisional de las pegatinas el 25 de julio, pero aún siguen presentes en bastantes municipios, por lo que el remedio judicial no ha sido suficiente. Durante el año 2020 camiones con eslóganes homofóbicos (por ejemplo, la relación entre la homosexualidad y la pedofilia) han comenzado a circular por la vía pública protegidos por la policía en algunos casos y un Tribunal de Breslavia ha estimado que este tipo de campañas quedan amparadas por la libertad de expresión por su "carácter educativo». Además, el nuevo ministro de Educación (miembro de PiS) ha calificado a la ideología LGTBI como «corrupción, depravación y comportamiento totalmente inmoral».

Aunque la declaración de zonas libres de LGTBI no tiene valor legal, sí tiene un gran valor simbólico, como una advertencia de los poderes públicos hacia el colectivo LGTBI de que en sus ciudades no hay cabida para ellos. Los estándares de la Unión prohíben la utilización de referencias discriminatorias en el discurso político, pero en Polonia son precisamente el presidente del Gobierno y los miembros del grupo político que lidera, que además ostenta la mayoría parlamentaria, quienes avalan este discurso. Por tanto, aunque desde el prisma de los derechos humanos constituye una violación flagrante que sea el presidente quien anime a los ciudadanos para que discriminen a las personas por su orientación sexual e identidad de género, en Polonia los mecanismos constitucionales de protección de los derechos fundamentales ya no se encuentran operativos, porque el PiS logró capturar el Tribunal Constitucional poco después de alcanzar el poder ${ }^{41}$.

41 Para un análisis más profundo de la captura del Tribunal Constitucional de Polonia, podemos consultar el capítulo 3 de la obra de Sadurski (2019: 58-95). 
En la campaña para las últimas elecciones parlamentarias (celebradas en octubre de 2019) PiS se vio obligado a buscar un nuevo enemigo que le sirviera para captar votos, pues la efectividad del argumento de la inmigración (utilizado en los anteriores comicios) había disminuido por el descenso del número de inmigrantes en Polonia.

El colectivo LGTBI se convirtió en el nuevo objetivo de PiS y la verdadera campaña en contra de sus derechos comenzó en febrero de 2019, tras la firma de una declaración en apoyo de los derechos LGTBI por parte del alcalde de Varsovia, Rafał Trzaskowski, junto con su intención de incluir un apartado sobre el colectivo LGTBI en la programación académica de la asignatura educación sexual. Esto sirvió como punto de partida para los miembros de PiS, encabezados por su presidente Jaroslaw Kaczyński, quien considera que los derechos LGTBI son una importación extranjera que pone en peligro Polonia y atacan a la familia y los niños ${ }^{42}$. La caza de brujas fue apoyada por el arzobispo de Krakovia, Marek Jedraszewski, que el 2 de agosto calificó al movimiento LGTBI como la «plaga arcoíris» ${ }^{43}$. Los resultados de las últimas elecciones nos muestran perfectamente la eficacia de este tipo de retórica: en 2019 PiS ha alcanzado la mayor cifra obtenida por cualquier partido en la historia democrática polaca, alcanzando un $43.5 \%$ de los votos que garantiza la mayoría absoluta del partido en solitario, con 235 de los 460 escaños que existen en el Parlamento polaco ${ }^{44}$.

\section{MEDIDAS ANTI-LGTBI EN HUNGRÍA}

La anterior Constitución húngara otorgaba grandes poderes a la Corte Constitucional, llegando a ser considerada la más poderosa del mundo gracias a sus poderes de revisión, pues sin importar el apoyo que una norma consiguiera en su tramitación, el Parlamento siempre obedecía las sentencias de la Corte y adoptaba la postura que estas marcaban a la hora de interpretar la Constitución, incluso cuando se trataba de temas polémicos que suscitaban controversias políticas, como sucedió con el reconocimiento de la igualdad de derechos de las parejas homosexuales y heterosexuales en el derecho civil (Örkény y Scheppele, 1999: 59-60). Teniendo esto en cuenta es lógico que la Corte Constitucional se convirtiera en el primero de los objetivos de la reforma iliberal de Fidesz — pasando de ser la institución más poderosa a

42 Véase: https://cutt.ly/2bK7AGB (última consulta: 27 de junio de 2020).

43 Véase: https://cutt.ly/DbK7JpX (última consulta: 27 de junio de 2020).

44 Véase: https://cutt.ly/KbK7VdK (última consulta: 27 de junio de 2020). 
ser un mero órgano simbólico ${ }^{45}$ - para no encontrar más obstáculos que la dificultad de mantener el apoyo de la ciudadanía a pesar de las reformas.

A diferencia de otros Estados del centro y este de Europa, en Hungría no existía hasta hace poco un movimiento anti-LGTBI, aunque sí existía este tipo de discurso. Una de las razones que lo explicaban era la falta de voluntad por parte del Gobierno para comenzar el movimiento, pero el fenómeno queda incardinado en un contexto más complejo, en el que también es relevante el papel de la Iglesia (Kováts y Petó, 2017: 117-118). En Polonia y Francia el movimiento anti-LGTBI fue catalizado con pequeñas movilizaciones previas que allanaron el camino para la verdadera movilización (ibid.: 125); y es precisamente esta la senda seguida por la Hungría de Fidesz para institucionalizar el discurso anti-LGTBI cuando surgió para este partido la necesidad de encontrar un nuevo enemigo con el que granjearse el apoyo electoral. Por tanto, se configura como uno de los recursos retóricos utilizados actualmente por el Gobierno húngaro para conseguir la polarización política y tiene potencial para movilizar a las masas y, especialmente, aquellos segmentos de la población cuyos votos aún no había sido captados por los elementos nacionalistas o xenófobos (Gradskova et al., 2020: 361).

Tras la llegada al poder de Fidesz, el Informe Tavares ${ }^{46}$ señaló respecto de Hungría (punto 53) su preocupación por los repetidos cambios en el ordenamiento jurídico que restringen los derechos de personas lesbianas, gais, bisexuales y transexuales (LGBT); por ejemplo, al intentar que las parejas del mismo sexo, sus hijos y otras formas de familia distintas de la tradicional quedasen excluidas de la definición de familia de la Ley Fundamental, subrayando que esto es «contrario a la jurisprudencia del Tribunal Europeo de Derechos Humanos y alimenta un clima de intolerancia hacia las personas LGBT» (Scheppele, 2018: 464). Asimismo, el Informe Sargentini señaló (cdo. 48) la preocupación del Comité de Derechos Humanos de Naciones Unidas por la falta de reconocimiento constitucional expreso de la prohibición de discriminación por motivos de orientación sexual e identidad de género y por la restrictiva definición de familia.

En los informes de ILGA-Europe encontramos reflejados varios acontecimientos, similares a los ocurridos en Polonia, que reflejan la gravedad de la situación. Por ejemplo, el 15 de mayo de 2019 el portavoz del Parlamento y anterior presidente László Kövér (Fidesz) afirmó que «moralmente no hay

45 Bárd y Carrera (2020: 6) afirman que desde 2011 la Corte Constitucional de Hungría es una mera marioneta en manos del Gobierno de Fidesz.

46 Informe: Documento de sesión sobre la situación de los derechos fundamentales: normas y prácticas en Hungría — tras la Resolución del Parlamento Europeo 2012/2130 (INI)- 
diferencia entre el comportamiento de un pedófilo y el comportamiento de alguien que pide estas cosas», refiriéndose al matrimonio igualitario y al derecho de adopción de los miembros del colectivo LGTBI ${ }^{47}$.

Estos hechos guardan relación con los resultados del Eurobarómetro sobre discriminación de 2019, que sitúan a Hungría como uno de los Estados miembros de la Unión Europea en que la aceptación de la población respecto del colectivo LGTBI ha disminuido desde 2015: únicamente el 48\% de la población en Hungría está de acuerdo con la igualdad de derechos entre las personas heterosexuales y las personas que forman parte del colectivo LGTBI, en la línea de lo ocurrido en Polonia, donde la aceptación de la igualdad de derechos es de un $49 \%{ }^{48}$. Uno de los datos más preocupantes es la baja tasa de denuncia policial de los ataques sexuales contra personas LGTBI, pues en Hungría únicamente un 5\% de los encuestados que habían sufrido un ataque de este tipo lo había denunciado (FRA, 2020: 46). Esta cifra nos demuestra que, aunque en Hungría existan los procedimientos legales para la persecución de este tipo de delitos, la población ha dejado de confiar en la resolución judicial de conflictos por la falta de independencia del Poder Judicial y de la Policía y, como consecuencia, se podría estar vulnerando aquí el derecho a la tutela judicial efectiva ${ }^{49}$.

Como colofón a la trayectoria anti-LGTBI que hemos expuesto, el 19 de mayo de 2020, en plena pandemia de COVID-19 y tras varias semanas de rechazo por parte del contexto internacional, el Parlamento de Hungría aprobó la ley general (omnibus bill) T/9934, cuyo art. 33 reemplaza la categoría sexo por la categoría inmutable de sexo asignado al nacer en el Registro Civil. Esto se traduce, en la práctica, en la prohibición del «cambio legal de género" ${ }^{50}$. Sin embargo, la situación en Hungría para el colectivo LGTBI ya era desoladora antes de esta reforma, como refleja el informe de la FRA: el $76 \%$ de los transexuales residentes en Hungría creen que su gobierno «definitivamente no combate con eficacia los prejuicios y la intolerancia frente a las personas LGTBI», en comparación con la media del $38 \%$ la Unión; así como el $84 \%$ de los transexuales encuestados señalan como la principal razón para este incremento en los prejuicios, la intolerancia y la violencia en el país

47 Véase: https://cutt.ly/gbK5Wu2 (última consulta: 27 de junio de 2020).

48 Véase: https://cutt.ly/LbK6aCc (última consulta: 27 de junio de 2020).

49 De forma similar a lo que podemos extraer de la declaración del ciudadano polaco que antes citamos. Esta situación ha sido confirmada por el TJUE respecto de Polonia en el caso C-192/18, así como en los casos acumulados C-585/18, C-624/18 y C-625/18.

50 Así denominamos al trámite que posibilita el cambio de la inscripción relativa al sexo de una persona, cuando este no coincide con su verdadera identidad de género. 
la «postura negativa sostenida por los políticos y/o partidos políticos» (FRA, 2020).

Más detalles de esta reforma son ofrecidos por la declaración del Standing Committee of the Conference of INGOs del Consejo de Europa, adoptada el 27 de abril de $2020^{51}$, donde se señala que esta ley no solo imposibilitaría el cambio legal de género, sino que, además, el «sexo al nacer» debería ser indicado en el registro nacional, así como en el documento de identidad de todos los ciudadanos de Hungría. La nueva normativa húngara sobre documentos oficiales, desde nuestro punto de vista, constituye un claro ejemplo de normativa discriminatoria y no encuentra fundamentación alguna, por lo que debe ser rechazada de plano $^{52}$. Además, si superamos el análisis fragmentario y analizamos el contexto en el que se ha producido esta reforma, vemos que a pesar de que en Hungría existía la posibilidad de modificar los documentos de identidad, estos procesos llevaban suspendidos dos años y, como consecuencia, la reforma que ahora analizamos solo acaba por confirmar una decisión que estaba en vigor de facto $^{53}$. Lo que más debe preocuparnos, además de su carácter discriminatorio, es la convergencia de esta norma con el actual discurso público anti-LGTBI en Hungría, ya que permitirá que los poderes públicos identifiquen sin problema a las personas transexuales con el mero hecho de consultar sus documentos de identidad, facilitando su estigmatización y su persecución.

En diciembre de 2020 el Parlamento de Hungría aprobó (con los 143 votos favorables de Fidesz) la novena reforma de la Ley Fundamental ${ }^{54}$,

51 Véase: https://cutt.ly/EbK6hMr (última consulta: 26 de junio de 2020).

52 El TJUE se ha pronunciado en contra de la discriminación indirecta, esto es, aquella producida por normas que en principio parecen prever una aplicación igual o uniforme para todos, pero que en la práctica y por el contexto en el que se insertan hacen nacer efectos discriminatorios. En casi todos los supuestos analizados por el TJUE (Boetel, C-360/90; Elbal Moreno, C-385/11) encontramos una situación aceptable en principio, como el establecimiento de condiciones retributivas diferentes para los trabajadores a tiempo parcial y los trabajadores tiempo completo (peores para los primeros), pero que en la práctica supone una discriminación hacia las mujeres, ya que estas son las que ocupan en mayor medida los trabajos a tiempo parcial. En nuestro caso, aunque la norma húngara determina que todos verán reflejado en sus documentos oficiales la categoría inmutable de "sexo asignado al nacer", produce un resultado de discriminación indirecta porque afecta de manera distinta a las personas transexuales que, como consecuencia de una ley aparentemente general, ven coartado su derecho a la identidad de género.

53 Véase: https://cutt.ly/qbK68cU (ultima consulta: 26 de junio de 2020).

54 El texto consolidado de la Ley Fundamental de Hungría puede encontrarse en inglés en la página web de la Corte Constitucional de Hungría: https://cutt.ly/ObLqwvR. 
introduciendo dos elementos preocupantes para el colectivo LGTBI: el apartado primero del art. $\mathrm{L}^{55}$ define la institución del matrimonio como «unión entre un hombre y una mujer» y señala respecto de las relaciones familiares que «la madre debe ser una mujer» y "el padre debe ser un hombre», eliminando de facto la posibilidad de que las parejas LGTBI adopten; y el apartado primero del art. XVI establece que «Hungría debe proteger el derecho de los niños a que su propia identidad se corresponda con el sexo asignado al nacer», añadiendo un obstáculo más para las personas transexuales. Asimismo, la Comisión de Justicia del Parlamento húngaro presentó el 10 de noviembre de 2020 una propuesta para eliminar la Autoridad para la Igualdad de Tratamiento (ETA), uno de los órganos más importantes en la defensa de los derechos LGTBI. Esta propuesta fue aprobada el 1 de diciembre de 2020 y entró en vigor el 1 de enero de 2021, encargando las tareas que venía desempeñando la ETA al Comisionado de Derechos Fundamentales, uno de los valedores de Orbán, caracterizado por su inactividad en asuntos LGTBI (ILGA-Europe, 2021).

Si consideramos de manera integral los hechos expuestos, en Hungría se podrían estar violando diversos derechos fundamentales, principalmente la tutela judicial efectiva y la igualdad, que estaría siendo vulnerada por los poderes públicos al establecer normas discriminatorias sin fundamentación alguna e incumplir su obligación de promover las condiciones necesarias para la inexistencia de discriminación, teniendo en cuenta además que son los propios líderes políticos los que se pronuncian en contra del colectivo LGTBI. Esta discriminación hacia las personas LGTBI ha sido confirmada por la ley que elimina la posibilidad del cambio legal de género, pues vulnera el derecho fundamental (general) a la igualdad en una de sus manifestaciones específicas (prohibición de discriminación por motivo de identidad de género) al privar a las personas transexuales de su derecho a determinar su sexo en los documentos oficiales; y esto, a su vez, vulnera su derecho a la intimidad individual al poner en conocimiento de toda autoridad pública que consulte sus documentos oficiales su condición de persona transexual. Finalmente, esta tendencia ha sido confirmada por la novena reforma de la Ley Fundamental para impedir la adopción de las personas LGTBI y, por tanto, podemos afirmar que Hungría se está convirtiendo en un Estado en el que las personas del colectivo LGTBI son marcadas y, por este motivo, ha dejado de ser un lugar seguro para aquellos que forman parte de los colectivos que se encuentran en el punto de mira del discurso de odio de Fidesz.

55 La Ley Fundamental de Hungría tiene también preceptos alfabéticos. 


\section{LA RESPUESTA DE LA UNIÓN EUROPEA ANTE LA VULNERACIÓN DE LOS DERECHOS LGTBI}

Como consecuencia de las reformas producidas en Hungría y Polonia, el Parlamento Europeo elaboró la «Resolución de 18 de diciembre de 2019, sobre la discriminación publica y el discurso de odio contra las personas LGBTI, incluido el concepto de "zonas sin LGBTI" (2019/2933(RSP))». En sus considerandos señala que la «seguridad de la comunidad LGTBI no es independiente de la seguridad de todos» los europeos y esta actúa como «indicador del deterioro de todos los derechos fundamentales» (cdo. F), así como se refiere a los hechos recientemente ocurridos en Polonia y los encuadra en un "contexto más amplio de ataques contra la comunidad LGTBI en Polonia, que incluyen la intensificación del discurso de odio por parte de cargos públicos y electos y medios de comunicación públicos, así como ataques y prohibiciones de Marchas del Orgullo o de programas de sensibilización y acciones como el Rainbow Friday» (cdo. P).

Más allá de los considerandos, los distintos apartados también contienen afirmaciones relevantes al respecto. El punto n. ${ }^{\circ} 1$ recuerda que «los derechos de las personas LGBTI son derechos fundamentales y que las instituciones de la Unión y los Estados miembros tienen, por tanto, el deber de ratificarlos y protegerlos de conformidad con los Tratados y la Carta, así como con el Derecho internacional». Esto confirma nuestra afirmación de que los Estados miembros no solo están obligados a respetar los derechos fundamentales por su pertenencia a la UE, sino también por las obligaciones de derecho internacional contraídas (principio de pacta sunt servanda). También se fijan en la vulneración de la tutela judicial efectiva, de modo que el punto n. ${ }^{\circ} 9$ «muestra su preocupación por que las víctimas de delitos de odio no denuncien tales actos debido a la ausencia de una protección adecuada y a la incapacidad de las autoridades para investigar adecuadamente dichos casos y conseguir condenas por los delitos de odio en los Estados miembros» ${ }^{56}$.

Además, el Parlamento Europeo urge sobre la conveniencia de crear un «mecanismo de la Unión global, permanente y objetivo sobre la democracia, el Estado de derecho y los derechos fundamentales, que incluya la protección de los derechos de las personas LGBTI» (pto. 14), y «pide a la Comisión y al

56 Esta situación trae causa de la falta de independencia judicial, señalada por el TJUE respecto de Polonia al responder la cuestión prejudicial planteada por el Tribunal Superior de Irlanda al hilo de una euroorden, donde utilizó como fundamentación el análisis de las reformas que PiS había llevado a cabo y la activación del procedimiento del art. 7.1 TUE respecto de dicho Estado. 
Consejo que utilicen todos los instrumentos y procedimientos a su alcance para garantizar la plena y adecuada aplicación de los principios y valores del Tratado» (pto. 15). Sin embargo, los mecanismos de la UE para garantizar el Estado de derecho han demostrado no ser efectivos frente a las vulneraciones que se producen en aquellos Estados miembros cuya expresa voluntad es atentar contra sus principales componentes (Uitz, 2019: 39).

Tras ello, se refiere especialmente a la creación de zonas libres de LGTBI y, por tanto, pide a la Comisión (pto. 16) que evalúe si su creación constituye «una violación de la libertad de circulación y de residencia en la Unión, infringiendo el artículo 3, apartado 2, del TUE, el artículo 21 del TFUE, los Títulos IV y V de la tercera parte del TFUE y el artículo 45 de la Carta». La declaración de zonas libres de LGTBI carece de valor jurídico vinculante y, por este motivo, no puede ser enjuiciada de manera separada por el TJUE, sin perjuicio de que pueda servir como complemento para analizar las demás medidas adoptadas y, por tanto, en la práctica puede servir para que este tribunal determine la necesidad de reforzar los estándares de prohibición de discriminación por motivos de orientación sexual e identidad de género en el seno de la Unión Europea.

Finalmente, pide a la Comisión (pto. 17) que "controle el uso de todos los flujos de financiación de la Unión, incluidos los Fondos Estructurales y de Inversión de la UE, y que dialogue periódicamente con las autoridades nacionales, regionales y locales para recordar a las partes interesadas su compromiso con la no discriminación y que dichos fondos no pueden utilizarse en ningún caso con fines discriminatorios». La petición debe ser puesta en relación con la reciente propuesta de la Comisión Europea de condicionar los fondos de la UE al cumplimiento del Estado de derecho en los Estados miembros ${ }^{57}$. La propuesta ha sido finalmente aprobada por el Consejo Europeo, pero se han tenido que hacer ciertas concesiones por la resistencia de Hungría y Polonia, dos Estados que, aunque formalmente no podían vetarla, amenazaron con bloquear la propuesta del Marco Financiero Plurianual 2021-2027, que sí requería la unanimidad para ser aprobado. También se ha manifestado en este sentido Ursula Van der Leyen (presidenta de la Comisión Europea) al justificar la denegación de fondos a seis ciudades polacas que se habían declarado LGTBI-free, recordando que los ciudadanos de la Unión Europea

57 La COM (2018) 324 final, «Propuesta de reglamento sobre la protección del presupuesto de la Unión en caso de deficiencias generalizadas del Estado de Derecho en los Estados miembros», es analizada en nuestro artículo de la Revista General de Derecho Público Comparado (Barroso Márquez, 2020a). 
son «libres de querer a quien quieran» ${ }^{58}$. Sin embargo, debemos subrayar que esta decisión se ha podido tomar porque la concreta convocatoria de dichas ayudas requiere que la Comisión garantice su coherencia con los instrumentos de otros ámbitos de acción de la Unión y, en particular, respecto de los derechos y libertades fundamentales, la igualdad entre mujeres y hombres o la lucha contra la discriminación ${ }^{59}$.

En plena crisis pandémica, el Parlamento Europeo elaboró la «Resolución de 17 de abril de 2020, sobre la acción coordinada de la Unión para luchar contra la pandemia de COVID-19 y sus consecuencias (2020/2616(RSP))", cuyo apartado 48 pide a los Estados miembros que garanticen durante la pandemia el acceso de las mujeres y niñas a la contracepción, «rechaza enérgicamente toda tentativa de retroceder en lo relativo a la salud y los derechos sexuales y reproductivos de las personas LGBTI» y condena «los ataques a los derechos de las personas transgénero e intersexuales en Hungría».

\section{CONCLUSIONES}

Tras este análisis, nos encontramos ante una cadena de conceptos interrelacionados. El Estado de derecho, en la concepción sustantiva adoptada por la UE, requiere el cumplimiento de los derechos fundamentales y, entre ellos, ocupa un papel fundamental el derecho a la igualdad, que implica la interdicción de la discriminación y, en especial, se incardina aquí la prohibición de discriminación por motivos de identidad de género y orientación sexual (derechos LGTBI).

Aunque la vulneración de los derechos fundamentales, considerada individualmente, no puede ser entendida como un ataque al Estado de derecho, el contexto iliberal previo al que nos hemos referido nos lleva a concluir que las reformas realizadas en Hungría y Polonia persiguen un único objetivo: el secuestro del poder a través de la democracia, utilizando como rehén al Derecho. Fidesz y PiS se suelen escudar tras la legalidad de las reformas adoptadas, ya que estas normalmente respetan la igualdad formal, pero a medida que la deriva iliberal avanza están aprobando también normas que vulneran la igualdad material y la tarea de ocultar de sus verdaderas intenciones es cada vez más complicada. La UE cuenta cada vez con

58 Véase: https://cutt.ly/sbLwag7 (última consulta: 9 de agosto de 2020).

59 Art. 11 del Reglamento (UE) 390/2014 del Consejo, de 14 de abril de 2014, por el que se establece el programa «Europa para los Ciudadanos» para el período 20142020 (https://cutt.ly/KbLwhpa). 
más argumentos para justificar su intervención en Hungría y Polonia y, de esta manera, proteger a los ciudadanos de sendos Estados de los Gobiernos que públicamente predican la ideología anti-LGTBI, evitando a su vez que florezca una sensación de impunidad y que su discurso se reproduzca en otros Estados miembros. Nuestra preocupación, por tanto, no hunde sus raíces en la vulneración de los derechos fundamentales por parte de una medida concreta, sino en que el modelo de Estado iliberal implantado en ambos Estados ha suprimido el sistema de pesos y contrapesos propio del constitucionalismo y, como consecuencia, ni el Tribunal Constitucional puede garantizar que las reformas legislativas cumplen los estándares constitucionales e internacionales, ni los órganos del poder judicial gozan de la independencia e imparcialidad suficientes como para poder respetar en todo caso la igualdad en la aplicación de las normas. Esto se traduce, en último término, en la pérdida de confianza por parte de la ciudadanía hacia los cauces judiciales de resolución de conflictos.

Sin embargo, como podemos extraer del breve repaso de los mecanismos con los que la Unión Europea cuenta para garantizar el Estado de derecho - y, como consecuencia, para garantizar el respeto de los derechos LGTBIen los Estados miembros, la Unión parece gozar ahora del mismo estatus que la monarquía del Rey Sol, pues a pesar de ser tradicionalmente considerado todopoderoso, Luis XIV únicamente alcanzaba a controlar aquello que estaba en su mano y, por tanto, su reinado no era tan absoluto como se cree. Siguiendo la analogía, la Unión actualmente se ha constituido como un verdadero gigante, cuya sombra se cierne sobre los Estados miembros, pero sus instrumentos actuales son demasiado aparatosos y limitados como para poder imponer el Estado de derecho en los miembros cuyos Gobiernos manifiestamente expresan su voluntad de contrariarlo.

En conclusión, la Unión Europea tiene ahora dos opciones: puede seguir apostando por el gigantesco aparato comunitario, dejando a los ciudadanos al albur de los Gobiernos nacionales aun cuando deciden vulnerar los derechos fundamentales; pero también puede (y debe) apostar por la creación de nuevos instrumentos que hagan desaparecer la sensación de impunidad y, por tanto, disuada a los Estados miembros de vulnerar los valores en que la Unión se fundamenta y devuelva a los ciudadanos la confianza en los mecanismos judiciales de resolución de conflictos en el plano nacional. Parece ser esta última la opción adoptada por las instituciones de la UE, como muestran las estrategias de condicionamiento, tanto a nivel macro (vincular fondos al Estado de derecho) como a nivel micro (exigir el respeto a los derechos fundamentales en convocatorias concretas). Queda por ver, finalmente, en qué medida afecta la salida de Fidesz del PPE a las relaciones de poder entre y en las instituciones de la Unión Europea. 


\section{Bibliografía}

Arroyo Gil, A. (2019). Orientación sexual y derechos humanos. Revista General de Derecho Constitucional, 30, 1-30.

Arroyo Gil, A. (2020). Las personas intersexuales desde una perspectiva de derechos humanos y fundamentales. IgualdadES, 2, 29-60. Disponible en: https://doi. org/10.18042/cepc/IgdES.2.02.

Baño León, J. M. (1987). La igualdad como derecho público subjetivo. Revista de Administración Pública, 114, 179-195.

Bárd, P. y Carrera, S. (2020). Showing true iliberal colours. Rule of law vs Orbán s pandemic politics. CEPS, 30-4-2020. Disponible en: https:/cutt.ly/tbLeqDe.

Barroso Márquez, J. F. (2020a). Nuevas dinámicas en la Unión Europea: propuesta para la creación de fondos condicionados al Estado de derecho. Revista General de Derecho Público Comparado, 28, 1-29.

Barroso Márquez, J. F. (2020b). Respuesta de Polonia a la COVID-19 y el principio de legalidad: iliberalismo y elecciones presidenciales. Anuario de la Facultad de Derecho de la Universidad de Extremadura, 36, 25-62. Disponible en: https:// doi.org/10.17398/2695-7728.36.25.

Barroso Márquez, J. F. (2021). Estado de derecho, iliberalismo y poderes de emergencia: oportunismo político en Hungría. En A. I. Dueñas Castrillo, D. Fernández Cañueto, P. Guerrero Vázquez y G. Moreno González (coords.). La Constitución en tiempos de pandemia (pp. 257-276). Madrid: Dykinson.

Blokker, P. (2016). EU Democratic Oversight and Domestic Deviation from the Rule of Law. Sociological Reflections. En C. Closa y D. Kochenov (eds.). Reinforcing Rule of Law Oversight in the European Union (pp. 249-269). Cambridge: Cambridge University Press. Disponible en: https://doi.org/10.1017/ CBO9781316258774.014.

Bobbio, N. (2012). Liberalismo y democracia. México: Fondo de Cultura Económica.

Böckenförde, E. W. (2000). Estudios sobre el Estado de derecho y la democracia. Madrid: Trotta.

Bogdandy, A. V. y Smrkolj, M. (2012). Reverse Solange. Protecting the Essence of Fundamental Rights Against EU Member States. Common Market Law Review, 49 (2), 489-519.

Bogdandy, A. V. y Ioannidis, M. (2014). Systemic deficiency in the rule of law: What it is, what has been done, what can be done. Common Market Law Review, 51 (1), 59-96.

Candia-Falcón, G. (2016). La concepción sustantiva del Estado de derecho: problemáticas y desafíos. Revista Jurídicas, 13 (2), 9-26. Disponible en: https://doi. org/10.17151/jurid.2016.13.2.2.

Campoy Cervera, I. (2017). En defensa del Estado de derecho. Debilidades y fortalezas del Estado de derecho a propósito de las criticas de Carl Schmitt. Madrid: Dykinson. Disponible en: https://doi.org/10.2307/j.ctt22nmd45. 
Claes, M. y Bonelli, M. (2019). The Rule of Law and the Constitutionalisation of the European Union. En W. Schroeder. Strengthening the Rule of Law in Europe (pp. 265-289). Oxford: Hart Publishing.

Corstens, G. (2017). Understanding the Rule of Law. Portland: Hart Publishing.

Cortés Martín, J. M. (2020). Sorteando los inconvenientes del artículo 7 TUE: el advenimiento del control jurisdiccional del Estado de derecho. Revista de Derecho Comunitario Europeo, 66, 473-517. Disponible en: https:/doi. org/10.18042/cepc/rdce.66.07.

Crabit, E. y Bel, N. (2019). The EU Rule of Law Framework. En W. Schroeder. Strengthening the Rule of Law in Europe (pp. 197-206). Oxford: Hart Publishing.

Craig, P. (1997). Formal and Substantive Conceptions of the Rule of Law: An Analytical Framework. Public Law, 3, 467-487.

Criado de Diego, M. (2011), La igualdad en el constitucionalismo de la diferencia, Revista Derecho del Estado, 26, 7-49.

Danwitz, T. V. (2014). The Rule of Law in the Recent Jurisprudence of the ECJ. Fordham International Law Journal, 35 (5), 1312-1348.

Díaz García, E. (1988). Estado de derecho y sociedad democrática. Barcelona: Taurus.

Díaz Lafuente, J. (2019). Avances en la protección de los derechos fundamentales de las personas LGBTI en la Unión Europea. En F. J. Matia Portilla, A. Elvira Perales y A. Arroyo Gil. La protección de los derechos fundamentales de las personas LGTBI (pp. 67-99). Valencia: Tirant lo Blanch.

Drinóczi, T. y Bień-Kacala, A. (2021). Illiberal constitutionalism and the European Rule of Law. En T. Drinóczi y A. Bień-Kacala. Rule of Law, Common Values, and Illiberal Constitutionalism (pp. 3-40). New York: Routledge. Disponible en: https://doi.org/10.4324/9781003052852-2.

European Union Agency for Fundamental Rights (2020). A long way to go for LGBTI equality. Luxembourg: Publications Office of the European Union.

FRA (2020). A long way to go for LGBTI equality. Luxembourg: Publications Office of the European Union.

García de Enterría, E. (1984). Principio de legalidad, Estado material de Derecho y facultades interpretativas y constructivas de la jurisprudencia en la Constitución. Revista Española de Derecho Constitucional, 10, 11-62.

Gibaja Cabrero, E. (2014). La orientación sexual ante el Tribunal Europeo de Derechos Humanos. Revista de Derecho Politico, 1, (91), 303-340. Disponible en: https://doi.org/10.5944/rdp.91.2014.13673.

Gradskova, Y., Kondakov, A. y Shevtsova, M. (2020). Post-socialist Revolutions of Intimacy: An Introduction. Sexuality and Culture, 24, 359-370. Disponible en: https://doi.org/10.1007/s12119-020-09706-8.

Greene, A. (2020). Permanent States of Emergency and the Rule of Law. Constitutions in an Age of Crisis. Oxford: Hart Publishing.

ILGA-Europe (2020). Annual Review of the Human Rights Situation of Lesbian, Gay, Bisexual, Trans and Intersex People in Europea and Central Asia. Belgium. 
ILGA-Europe (2021). Annual Review of the Human Rights Situation of Lesbian, Gay, Bisexual, Trans and Intersex People in Europea and Central Asia. Belgium.

Jack, B. (2013). Article 260 (2) TFEU: An Effective Judicial Procedure for the Enforcement of Judgments? European Law Journal, 19 (3), 404-421. Disponible en: https://doi.org/10.1111/eulj.12030.

Konstantinides, T. (2020). The Rule of Law in the European Union. The Internal Dimension. Oxford: Hart Publishing.

Kovats, E. y Peto A. (2017). Anti-gender discourse in Hungary: A discourse without a movement? En R. Kuhar y D. Paternotte (eds.). Anti-gender campaigns in Europe: Mobilizing against equality (pp. 117-131). London: Rowman and Littlefield.

Kryigier, M. (2018). Tempering Power. En M. Adams, A. Meuwese y E. H. Ballin (eds.). Constitutionalism and the Rule of Law. Bridgingn Idealism and Realism (pp. 34-59). Cambridge: Cambridge University Press. Disponible en: https:// doi.org/10.1017/9781316585221.002.

Krzywoń, A. (2020). La defensa y el desarrollo del principio de independencia judicial en la Unión Europea. Revista Española de Derecho Constitucional, 119, 85-117. Disponible en: https://doi.org/10.18042/cepc/redc.119.03.

Lucas Verdú, P. (1983). Estado de derecho y Justicia Constitucional. Revista de Estudios Politicos, 33, 7-48.

Manzano Barragán, I. (2009). La protección de las minorías sexuales en la Unión Europea. Revista de Derecho Comunitario Europeo, 32, 151-178.

Martín Rodríguez, P. J. (2016). El Estado de derecho y el sistema jurídico de la Unión Europea. En D. J. Liñán Nogueras y P. J. Martín Rodríguez (eds.). Estado de derecho y Unión Europea (pp. 157-188). Madrid: Tecnos.

Martín y Pérez de Nanclares, J. (2019). La Unión Europea como comunidad de valores: a vueltas con la crisis de la democracia y del Estado de derecho. Teoría y Realidad Constitucional, 43, 121-159. Disponible en: https://doi.org/10.5944/ trc.43.2019.24401.

Morgenbesser, L. (2020). The Rise of Sophisticated Authoritarianism in Southeast Asia. Cambridge: Cambridge University Press. Disponible en: https://doi. org/10.1017/9781108630061.

Müller, J. W. (2014). The EU as a Militant Democracy, or: are there Limits to Constitutional Mutations within EU Member States? Revista de Estudios Politicos, $165,141-162$.

Müller, J. W. (2016). Protecting the Rule of Law (and Democracy!) in the EU. The Idea of a Copenhagen Commission. En C. Closa y D. Kochenov (eds.). Reinforcing Rule of Law Oversight in the European Union (pp. 206-224). Cambridge: Cambridge University Press. Disponible en: https://doi.org/10.1017/ CBO9781316258774.012.

Örkény, A.y Scheppele, K. L. (1999). Rules of Law: The Complexity of Legality in Hungary. En M. Krygier y A. Czarnota. The Rule of Law after Communism (pp. 55-76). New York: Routledge. Disponible en: https://doi.org/10.4324/9781315085319-3. 
Pech, L. y Grogan, J. (2020). Meaning and Scope of the EU Rule of Law. Reconnect, 5-6-2020. Disponible en: https://bit.ly/3gQYAqA.

Rey Martínez, F. (2017). Igualdad y prohibición de discriminación: de 1978 a 2018. Revista de Derecho Politico, 100, 125-171. Disponible en: https://doi. org/10.5944/rdp.100.2017.20685.

Sadurski, W. (2019). Poland's Constitutional Breakdown. Oxford: Oxford University Press. Disponible en: https://doi.org/10.1093/oso/9780198840503.001.0001.

Scheppele, K. L. (2018). Constitutional Coups in EU Law. En M. Adams, A. Meuwese y E. H. Ballin (eds.). Constitutionalism and the Rule of Law. Bridgingn Idealism and Realism (pp. 446-478). Cambridge: Cambridge University Press. Disponible en: https://doi.org/10.1017/9781316585221.015.

Schütze, R. (2019). Constitutionalism(s). En R. Masterman y R. Schütze (eds.). Comparative Constitutional Law (pp. 40-66). Cambridge: Cambridge University Press. Disponible en: https://doi.org/10.1017/9781316716731.003.

Selznick, P. (1999). Legal Cultures and the Rule of Law. En M Krygier y A. Czarnota (eds.). The Rule of Law after Communism (pp. 21-37). New York: Routledge.

Serowaniec, M. y Witkowski, Z. (2020). Can legislative standards be subject to 'quarantine'? The functioning of the Tablet Sejm in Poland in the COVID-19 era. The Theory and Practice of Legislation, 8, 155-170. Disponible en: https:// doi.org/10.1080/20508840.2020.1805851.

Šišková, N. (2019). The EU Concept of the Rule of Law and the Procedures de lege data and de lege ferenda for its Protection. International and Comparative Law Review, 19 (2), 116-130. Disponible en: https://doi.org/10.2478/iclr-20190017.

Steiner, E. (2019). The Rule of Law in the Jurisprudence of the European Court of Human Rights. En W. Schroeder (ed.). Strengthening the Rule of Law in Europe (pp. 135-154). Oxford: Hart Publishing.

Tóth, G. A. (2017). Illiberal Rule of Law? Changing Features of Hungarian Constitutionalism. En M. Adams, A. Meuwese y E. H. Ballin (eds.). Constitutionalism and the Rule of Law. Bridgingn Idealism and Realism (pp. 386-415). Cambridge: Cambridge University Press. Disponible en: https://doi. org/10.1017/9781316585221.013.

Uitz, R. (2019): Guest Editorial. The Perils of Defending the Rule of Law Through Dialogue. European Constitutional Law Review, 15, 1-16. Disponible en: https://doi.org/10.1017/S1574019619000051.

Uprimny Yepes, R. (2013-2014). Estado de derecho. Eunomía. Revista en Cultura de la Legalidad, 5, 168-176.

Weiler, J. H. H. (2016). Epilogue: Living in a Glass House. Europe, Democracy and the Rule of Law. En C. Closa y D. Kochenov. Reinforcing Rule of Law Oversight in the European Union (pp. 313-326). Cambridge: Cambridge University Press. Disponible en: https://doi.org/10.1017/CBO9781316258774.017.

Zakaria, F. (1997). The Rise of Illiberal Democracy. Foreign Affairs, 76 (2), 22-43. Disponible en: https://doi.org/10.2307/20048274. 